\title{
FG-4592 Accelerates Cutaneous Wound Healing by Epidermal Stem Cell Activation via HIF-1 $\alpha$ Stabilization
}

\author{
Di Tang a Junhui Zhang ${ }^{\mathrm{a}}$ Tiantian Yan ${ }^{\mathrm{a}, \mathrm{b}}$ Jingyu Wei ${ }^{\mathrm{a}} \quad$ Xupin Jiang $^{\mathrm{a}}$ \\ Dongxia Zhang ${ }^{a}$ Qiong Zhang ${ }^{a}$ Jiezhi Jia ${ }^{a}$ Yuesheng Huanga
}

aInstitute of Burn Research, State Key Laboratory of Trauma, Burns and Combined Injury, Southwest Hospital, Third Military Medical University (Army Medical University), Chongqing, 'Dilitary Burn Center, The No. 159th Hospital of the People's Liberation Army, Zhumadian, China

\section{Key Words}

FG-4592 • Epidermal Stem Cells • Proliferation • Motility • HIF-1 $\propto$ •Wound Healing

\begin{abstract}
Background/Aims: Regional hypoxia promptly develops after trauma because of microvascular injury and increased oxygen consumption. This acute hypoxia plays a positive role in early skin wound healing. One of the mechanisms underlying the beneficial effects of acute hypoxia on wound healing may be increased hypoxia-inducible factor-1 (HIF-1 $\alpha$ ) expression. HIF-1 $\alpha$ may affect the wound-healing process through many aspects, including angiogenesis, metabolism, and extra-cellular matrix synthesis and remodelling. Epidermal stem cells (EpSCs) are important participants in wound repair; however, whether these cells are regulated by hypoxia is unclear. This study aimed to elucidate the regulatory mechanism by which hypoxia acts on EpSCs. Methods: CCK8 assays, western blots and live cell station observation were employed to compare the viability, proliferation and motility of EpSCs cultured under normoxic conditions $\left(21 \% \mathrm{O}_{2}\right)$ with those cultured under hypoxic conditions $\left(2 \% \mathrm{O}_{2}\right.$ ). Moreover, we used FG-4592 (a prolyl hydroxylase inhibitor that stabilizes HIF-1 $\alpha$ in normoxia), KC7F2 (a selective inhibitor of HIF-1 $\alpha$ transcription) and siRNA against HIF$1 \alpha$ to regulate HIF-1 $\alpha$ expression. Results: Acute hypoxia caused EpSCs to switch from a quiescent state to an activated state with higher viability and motility, as well as an earlier proliferation peak. We demonstrated that the HIF-1 signalling pathway mediated hypoxiainduced activation of EpSCs. Finally, the in vivo experiments showed that exogenous FG-4592 effectively accelerates wound healing, shortens healing times and even induces epidermal hyperplasia. Conclusion: This study demonstrated that both hypoxia and exogenous FG-4592 improve EpSC proliferation and motility by stabilizing HIF-1 $\alpha$, and its results suggest that HIF$1 \alpha$ is an important target through which wound healing can be accelerated and that FG-4592 is a promising new drug for wound repair.




\section{Cellular Physiology Cell Physiol Biochem 2018;46:2460-2470 \\ and Biochemistry Published onIne: Vay 11, $2018 \quad \begin{aligned} & \text { DOI: } 2018 \text { The Author(s). Published by S. Karger AG, Basel } \\ & \text { www.karger.com/cpb }\end{aligned}$ \\ Tang et al.: FG-4592 Accelerates Cutaneous Wound Healing}

\section{Introduction}

Cutaneous wounds resulting from conditions such as trauma, burns, surgery, and diabetes are common clinical problems [1]. However, how wound healing is effectively promoted, as well as how chronic refractory wounds are treated, is not well understood.

We and others previously demonstrated that following acute injury, the skin wound microenvironment becomes more hypoxic due to vascular disruption and high oxygen consumption by the cells at the edges of the wound [2-4]. In contrast to hypoxia-induced injury $[5,6]$, this acute hypoxia plays a positive role in the early stage of wound healing, which induces the production of numerous cytokines, including vascular endothelial growth factor (VEGF), transforming growth factor-b (TGF-b), and platelet-derived growth factor (PDGF), in the wound microenvironment [2]. Impaired responses to tissue hypoxia are believed to be a major factor responsible for diminished wound healing in chronic wounds [7-12]. Therefore, elucidating the molecular mechanism underlying cell responses to hypoxia may facilitate the development of strategies for promoting wound healing.

Epidermal stem cells (EpSCs), which are adult stem cells, reside in the basal layer of the interfollicular epidermis [13]. EpSCs and their daughter cells, which are also known as keratinocytes, play an essential role in re-epithelialization by first migrating from their niche towards the wound and then undergoing proliferation and differentiation. Previous studies have shown that biological processes, such as pregnancy, lactation $[14,15]$, hypoxia [16] and circadian rhythms [17], can impact stem cells. In this study, we focused on how EpSCs respond to hypoxia. Hypoxia triggers tumour growth [18-20]. Moreover, the proliferation and migration of stem cells are somewhat similar to the growth and metastasis of tumour cells. Those factors inspired us to explore how hypoxia affects EpSCs.

Hypoxia-inducible factor-1 (HIF-1), a heterodimeric transcription factor complex, has been recognized as a master regulator of hypoxia for more than 20 years [21]. HIF-1 $\beta$ protein levels are relatively constant; however, HIF- $1 \alpha$ is hydroxylated on conserved proline residues under normoxic conditions, which results in von Hippel-Lindau protein E3 ubiquitin ligase recruitment and immediate proteasomal degradation. This prolyl hydroxylation is mediated by an enzyme family of HIF-prolyl hydroxylases (prolyl-4-hydroxylation domain (PHD) proteins), whose activity is dependent on dioxygen, ferrous iron and 2-oxoglutarate [22]. PHDs are less active in hypoxic conditions, in which HIF-1 $\alpha$ translocates to the nucleus and dimerizes with HIF-1 $\beta$, which allows the complex to bind to the hypoxia response elements (HREs) in the regulatory sequences of several genes vital to cell survival [23].

HIF-1 $\alpha$ affects the wound-healing process in many ways, as it affects the expression of multiple angiogenic growth factors, cell motility, and the recruitment of end othelial progenitor cells [2]. Moreover, recent studies using gene-knockout methods have demonstrated that both PHD-2 [24] and HIF-1 $\alpha$ [25] have an effect on wound healing.

In light of the evidence linking HIF- $1 \alpha$ to wound healing, new drugs that manipulate its expression and function are needed. FG-4592, a novel prolyl hydroxylase inhibitor, is currently in phase three clinical trials regarding the treatment of renal anaemia in patients with chronic kidney disease [26]. In recent years, some studies have shown that FG-4592 stabilizes HIF-1 $\alpha$ and increases tolerance to hypoxia, thereby improving the prognosis of many diseases, such as renal anaemia [26, 27], spinal cord injury [21], and retinal disease $[28,29]$. However, there have been no attempts to investigate the role of FG-4592 in wound healing. Accordingly, the present study was designed to analyse whether treatment with the novel PHD inhibitor FG-4592 accelerates wound healing in mice and promotes EpSCs proliferation and motility.

\section{Materials and Methods}

Ethics statement

All animal-based investigations were designed and performed in accordance with the Guide for the Care and Use of Laboratory Animals published by the National Institutes of Health (NIH Pub. No. 85-23, 


\section{Cellular Physiology Cell Physiol Biochem 2018;46:2460-2470 and Biochemistry Published on $\begin{aligned} & \text { DOI: 10.1159/000489652 } \\ & \text { (c) } 2018 \text { The Author(s). Published by S. Karger AG, Basel } \\ & \text { www.karger.com/cpb }\end{aligned}$ \\ Tang et al.: FG-4592 Accelerates Cutaneous Wound Healing}

revised 1996). The entire project was reviewed and approved by the Animal Experimental Ethics Committee of the Third Military Medical University in Chongqing, China.

\section{Culture and characterization of mouse EpSCs}

Mouse EpSCs were isolated from newborn (aged 0-2 days) mouse skin, according to a method described previously [1]. Briefly, the mouse skin tissues were incubated in $0.5 \%$ dispase II in $0.9 \% \mathrm{NaCl}$ solution overnight at $4^{\circ} \mathrm{C}$. The epidermal sheet was carefully separated from the dermis, minced, and then digested in $0.5 \%$ trypsin in phosphate-buffered saline (PBS) for $5-10$ minutes at $37^{\circ} \mathrm{C}$. The epidermal suspension was subsequently gently agitated to create a single-cell suspension. Trypsin was inactivated in calcium-free RPMI 1640 medium containing 10\% chelexed FBS. The suspension was filtered through a 70- $\mu \mathrm{m}$ cell strainer and then centrifuged at $1000 \mathrm{rpm}$ for 5 minutes. The complete medium for the mouse EpSCs contained defined keratinocyte serum-free medium (DK-SFM, 10744-019; Gibco), calcium chloride (0.05 mM), mouse epidermal growth factor (10 ng/ml, 354001; BD), cholera toxin (10 $10^{-10} \mathrm{M}, \mathrm{C} 9903$; Sigma) and penicillin and streptomycin solution $(100 \mathrm{IU} / \mathrm{ml}, 15140122$; Gibco). The cells were seeded in plates or flasks coated with $100 \mu \mathrm{g} / \mathrm{ml}$ type IV collagen (C5533; Sigma) at a density of $10^{5} \mathrm{cells} / \mathrm{cm}^{2}$ and were allowed to adhere for 15 minutes at $37^{\circ} \mathrm{C}$. The non-adherent cells were subsequently discarded, and the rapidly adhering cells were cultured in complete medium at $37^{\circ} \mathrm{C}$ in $5 \% \mathrm{CO}_{2}$.

EpSC characterization was performed according to the methods described by Kaur [30]. After the cells were cultured for 3 days, they were digested and stained with FITC-conjugated CD71 (561936; BD) and PEconjugated CD49f (555736; BD) antibodies. Flow cytometry data were acquired using an Attune Acoustic Focusing Cytometer (Applied Biosystems, Life Technologies, CA, USA), and the data were analysed using FlowJo software (Tree Star Incorporation, USA).

\section{Hypoxia treatment}

Hypoxic conditions were established using a Forma Series II Water Jacket $\mathrm{CO}_{2}$ incubator (model: 3131; Thermo Scientific), with which we could precisely control oxygen levels and temperature. The hypoxic conditions were generated at $37^{\circ} \mathrm{C}$ in $5 \% \mathrm{CO}_{2}$, and the designated oxygen content was balanced with $\mathrm{N}_{2}$. All of the media used in the hypoxia experiments were preincubated in chambers with the designated oxygen content overnight.

\section{Cell proliferation and viability assessment by CCK8 assay}

EpSCs were seeded in 96-well cell culture plates. Cell proliferation was determined in each group using Cell Counting Kit-8 (CCK-8; Beyotime, China), and the absorbance was measured at $450 \mathrm{~nm}$ using a microplate reader (Thermo, USA).

\section{Western blot analysis}

The cells were washed with ice-cold PBS and harvested on ice. The protein concentration of the resulting lysates was determined using a RCDC protein assay kit (Sigma, USA). A prestained standard protein molecular weight marker and the protein samples were subsequently loaded into wells and separated by $8 \%$ SDS-PAGE. The blots were then transferred to polyvinylidene difluoride (PVDF) membranes by electroblotting. The membranes were blocked with $5 \%$ nonfat dried milk or bovine serum albumin (BSA) and then incubated with the following primary antibodies overnight at $4^{\circ} \mathrm{C}$ : rabbit anti-PCNA $(1: 2000$ dilution; Proteintech, USA), rabbit anti-HIF-1 $\alpha$ (1:1000 dilution; Proteintech, USA) and mouse anti- $\beta$ actin (1:5000 dilution; Abcam, UK). The membranes were then incubated with horseradish peroxidaseconjugated secondary IgG (1:5000 dilution; Proteintech, USA), which was used as the secondary antibody. The results were analysed using a ChemiDoc imaging system (Bio-Rad, USA).

\section{Cell motility assay and quantitative analysis}

For the cell motility assays, EpSCs were seeded in 24-well plates. After each group received the appropriate treatment, the cells were evaluated by time-lapsed imaging with a Zeiss imaging system (Carl Zeiss Meditec, Jena, Germany) equipped with a $\mathrm{CO}_{2}$-and temperature-controlled chamber. Images were acquired every 5 minutes for $3 \mathrm{~h}$. The trajectories of the cells were subsequently determined by tracing the positions of the cell nuclei at frame intervals of 5 minutes using NIH ImageJ software. The velocity $(\mu \mathrm{m} / \mathrm{h})$ of each cell, which reflects cell motility, was calculated as the total length $(\mu \mathrm{m})$ of each trajectory divided by time (h). 


\section{Cellular Physiology Cell Physiol Biochem 2018;46:2460-2470 and Biochemistry Published \begin{tabular}{l|l} 
DOI: 10.1159/000489652 & $\begin{array}{l}\text { C } 2018 \text { The Author(s). Published by S. Karger AG, Basel } \\
\text { www.karger.com/cpb }\end{array}$
\end{tabular} \\ Tang et al.: FG-4592 Accelerates Cutaneous Wound Healing}

\section{Cell treatments}

According to previous research results [4], the oxygen tension in the wound edge is approximately $10 \mathrm{mmHg}$ (equivalent to $2 \%$ oxygen concentration). To simulate the hypoxic microenvironment of wound healing, we chose a $2 \%$ oxygen concentration as the hypoxic condition in cell experiments. EpSCs in the hypoxia group were placed into a hypoxic incubator with an oxygen concentration of $2 \%$ at $24 \mathrm{~h}$ after seeding. The cells in both the normoxia and hypoxia groups were then harvested or tested at the indicated time points.

For the HIF-1 $\alpha$ regulation experiments, $5 \mu \mathrm{M}$ or $10 \mu \mathrm{M}$ FG-4592 (S1007; Selleck) or KC7F2 (S7946; Selleck) was added to the medium at $24 \mathrm{~h}$ after the cells were seeded (at which time they had reached approximately 30\%-50\% confluence). The culture plates in the hypoxia group were placed into another hypoxic incubator with an oxygen concentration of $2 \%$. The EpSCs were harvested or tested after $24 \mathrm{~h}$ of treatment.

To specifically inhibit HIF-1 $\alpha$ expression, we purchased HIF- $1 \alpha$ siRNA and a negative-control siRNA (siRNAcon) from Shanghai GenePharma, Co. Ltd. (Shanghai, China). The EpSCs were seeded in plates or flasks, according to the experiment. When the cells reached approximately 30\%-50\% confluence, they were transfected with HIF-1 $\alpha$ siRNA or siRNAcon for $6 \mathrm{~h}$, according to the manufacturer's protocol, after which they were cultured in serum-free medium for $24 \mathrm{~h}$. The cells were subsequently treated with FG-4592 or hypoxia at $12 \mathrm{~h}$ before harvesting or further testing.

\section{Animal model}

Adult male BALB/c mice (10 to 12 weeks of age, $20 \pm 2 \mathrm{~g}$ ) were prepared for surgery ( $\mathrm{n}=8$ ). These mice were randomly divided into the following two groups: a control group and an FG-4592 group. Two 4-mm full-thickness excisional wounds extending through the panniculus carnosus were made on the dorsum of each mouse after depilation, as previously described [31]. A donut-shaped (inner diameter, $7 \mathrm{~mm}$; outer diameter, $12 \mathrm{~mm}$ ) self-adhesive silicone splint (3 M, Shenzhen, China) was placed and fitted to the skin such that the wound was centred within the splint. The advantages of this animal model include easy operation, no new damage to skin around the wound, and a reference for measuring the size of the wound is provided. The animals were then housed individually.

FG-4592 (S1007; Selleck) was first prepared as a $50 \mathrm{mg} / \mathrm{ml}$ stock solution, according to a method described previously [29], after which it was diluted to a concentration of $1 \mathrm{mg} / \mathrm{ml}$ in sterile PBS and stored at $-80^{\circ} \mathrm{C}$. FG-4592 and PBS were intraperitoneally administered to the mice in the FG-4592 and control groups, respectively, at a dose of $10 \mathrm{mg} / \mathrm{kg}$ daily.

Digital imaging was preformed every other day until wound closure. The time to wound closure was defined as the time at which the wound bed had completely re-epithelialized and filled with new tissue. Wound area was quantified by tracing the wound margins and was calculated as a percentage of the original wound area using Image J software.

\section{Statistical analysis}

Statistical comparisons were performed by Student's t test or one-way ANOVA using GraphPad Prism 6.0 software (GraphPad Software Inc.). The data are presented as the mean \pm standard error of the mean (SEM). In all cases, $\mathrm{P}<0.05$ was considered statistically significant.

\section{Results}

\section{Acute hypoxia induces EpSCs activation}

To explore how oxygen tension affects EpSCs, we first used CCK-8 to detect EpSC viability. Interestingly, EpSCs incubated in hypoxic conditions $\left(2 \% \mathrm{O}_{2}\right)$ displayed better viability than cells incubated in normoxic conditions (Fig. 1A). This advantage appeared during the first $24 \mathrm{~h}$ of the experiment. Western blotting showed that PCNA expression was much higher in the hypoxia group than in the normoxia group at $12 \mathrm{~h}$ after hypoxia treatment and slightly higher in the hypoxia group than in the normoxia group at $24 \mathrm{~h}$ after hypoxia treatment. (Fig. $1 \mathrm{~B})$. Hypoxia had a positive effect on cell motility, as it expanded cell ranges of movement (Fig. 1 C) and increased EpSC velocities (Fig. 1 D). These results indicate that acute hypoxia 
activates EpSCs by promoting cell proliferation and motility.

\section{HIF-1 $\alpha$ is involved in hypoxia-} induced EpSC activation

We initially detected the expression of HIF-1 $\alpha$, which served as a positive control, to determine whether hypoxia treatment was effective (Fig. 1 B). We then determined whether HIF- $1 \alpha$ mediates hypoxia-induced increases in EpSC proliferation and motility. We used FG-4592 (a prolyl hydroxylase inhibitor that stabilizes HIF-1 $\alpha$ in normoxia) and KC7F2 (a selective inhibitor of HIF- $1 \alpha$ transcription) to regulate HIF-1 signalling. A CCK-8 assay showed that FG-4592 increased EpSC cell viability in normoxia and that KC7F2 decreased EpSC viability in a dose-dependent manner both in normoxia and in hypoxia (Fig. 2A). Western blot showed that FG-4592 increased

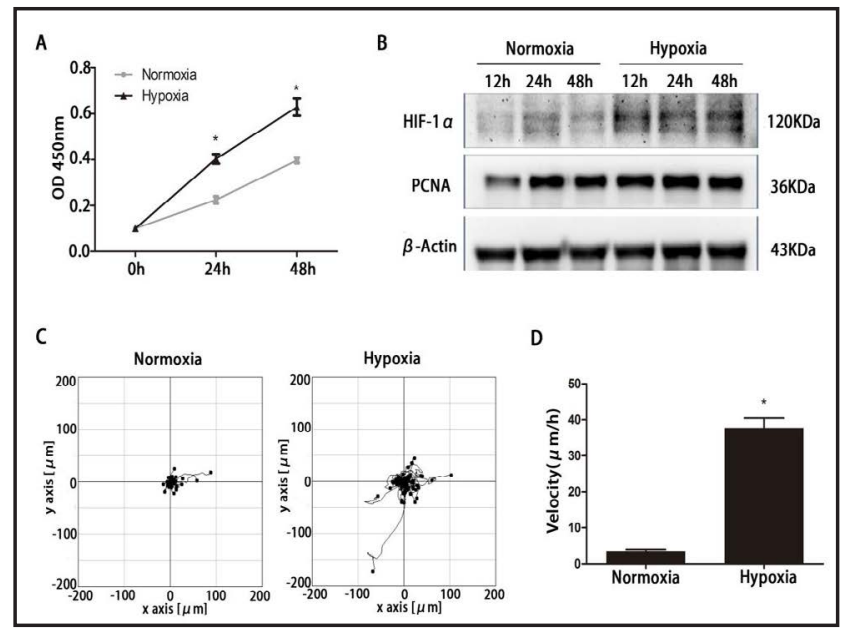

Fig. 1. Acute hypoxia-induced EpSCs activation. (A) Viability of EpSCs cultured in normoxic and hypoxic conditions $\left(2 \% \mathrm{O}_{2}\right)$, as determined by CCK- 8 assays at the indicated times. The viability of each group is shown as the mean $\pm \mathrm{SD}$. *, $\mathrm{P}<0.05$ versus the normoxia group. (B) Western blotting results showing that PCNA expression peaked earlier in the hypoxia group. (C) (D) The movement trajectories of the EpSCs in the normoxia and hypoxia groups were recorded by a Zeiss imaging system. The velocity of each group is shown as the mean \pm SD. ${ }^{*}, \mathrm{P}<0.05$ versus the normoxia group.
Fig. 2. HIF- $1 \alpha$ is involved in hypoxiainduced EpSC activation. FG-4592 and KC7F2 were used to regulate HIF-1 $\alpha$ expression. (A) The viability of the EpSCs in each group was detected by CCK-8 assays. The EpSCs were under the indicated conditions for $24 \mathrm{~h}$. The viability of each group is shown as the mean $\pm \mathrm{SD}$. ${ }^{*}, \mathrm{P}<0.05$ versus the normoxia control group; \#, $\mathrm{P}<0.05$ versus the hypoxia control group. (B) Western blotting results showing that FG-4592 simulated hypoxia-induced increases in HIF- $1 \alpha$ and PCNA expression. (C) Western blot results showing that KC7F2 inhibited hypoxia-induced increases in HIF- $1 \alpha$ and PCNA expression. (D) (E) The movement trajectories of the EpSCs in each group were recorded by a Zeiss imaging system. The velocity of each group is shown as the mean $\pm \mathrm{SD}$. N, normoxia; $\mathrm{H}$, hypoxia; *, $\mathrm{P}<0.05$ versus the normoxia group; \#, $\mathrm{P}<0.05$ versus the hypoxia group.

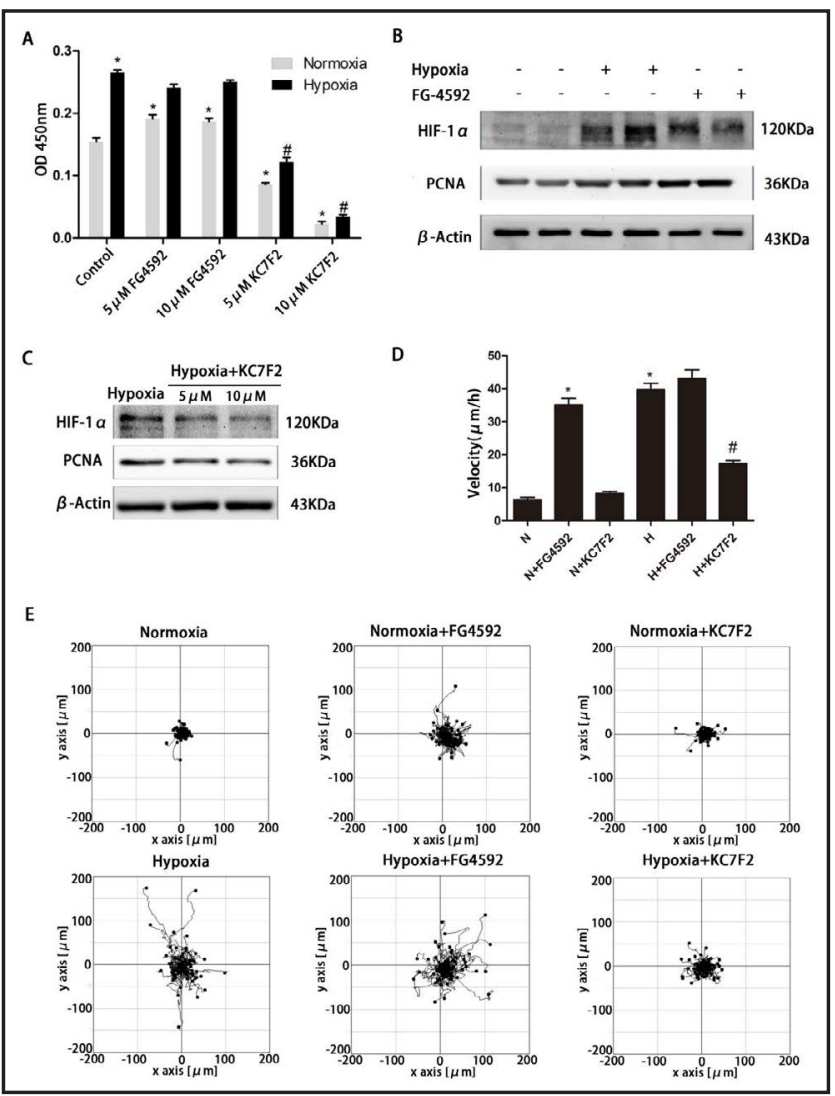


HIF- $1 \alpha$ and PCNA expression (Fig. 2B) and thus had the same effect as hypoxia treatment. In contrast, KC7F2 decreased HIF- $1 \alpha$ and PCNA expression (Fig. 2C). Moreover, FG4592 promoted EpSC motility in normoxia, while KC7F2 reversed hypoxia-induced increases in cell motility (Fig. D and E). The above data demonstrate HIF- $1 \alpha$ plays an important role in hypoxia-induced EpSC activation.

FG-4592 simulates the effects of hypoxia on EpSCs specifically through HIF-1 $\alpha$ stabilization

FG-4592 simulates the effects of acute hypoxia; however, whether it acts specifically through HIF$1 \alpha$ stabilization was unknown. Therefore, we used HIF- $1 \alpha$ siRNA (siRNA against HIF-1 $\alpha$ ) to downregulate HIF-1 signalling. A CCK-8 assay showed that HIF- $1 \alpha$ siRNA effectively reversed hypoxia- and FG-4592-induced increases in EpSC viability (Fig. 3A). Western blotting showed that HIF- $1 \alpha$ siRNA also reduced PCNA expression under both FG-4592 treatment (Fig. 3B) and hypoxic conditions (Fig. 3C). Cell motility assays and quantitative analysis showed that HIF- $1 \alpha$ siRNA inhibited the cell motility increases induced by FG4592 and hypoxia (Fig. 3D and E). These results reveal that FG-4592 exerted its effects mainly through HIF- $1 \alpha$ stabilization.

\section{FG-4592 effectively accelerates} wound healing in vivo

We used a humanized wound-healing model that heals through granulation tissue and re-epithelialization to test in vivo wound closure rates. We noted a significant difference in the wound closure rate between the control and FG-4592 groups on days 2, 4, 6, and 8 post-injury (Fig. 4A and B). The wounds on the mice in the control group (intraperitoneally injected with PBS) closed on post-injury day $9.88 \pm 0.55$, whereas the wounds on FG-4592treated mice (intraperitoneally injected with FG-4592) healed on post-injury day $8.13 \pm 0.35$ $\left({ }^{*} \mathrm{P}<0.05\right)$ (Fig. 4C). Moreover, the average neo-epidermis length in the mice in the control group was significantly shorter than that in the mice in the FG-4592 group (Fig. 4D and E; Control, $0.56 \mathrm{~mm}$ vs FG-4592, $0.88 \mathrm{~mm}, \mathrm{P}<0.05$ ) on day 4 post-injury. These results indicate that FG-4592 accelerates wound healing.

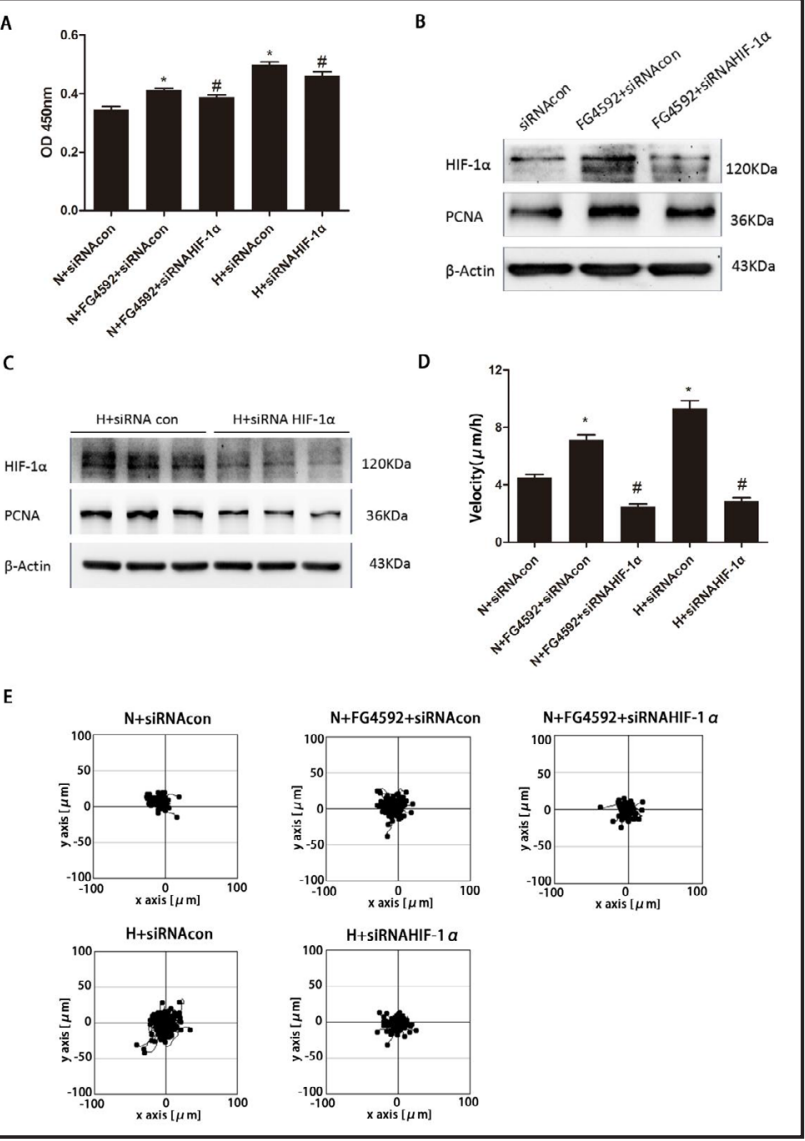

Fig. 3. FG-4592 simulated the effect of hypoxia on EpSCs specifically through HIF-1 $\alpha$ stabilization. (A) The viability of the EpSCs in each group, as determined by CCK-8 assays. siRNAcon served as a negative control. The viability of each group is shown as the mean \pm SD. $\mathrm{N}$, normoxia; $\mathrm{H}$, hypoxia; ${ }^{*}, \mathrm{P}<0.05$ versus the $\mathrm{N}+$ siRNAcon group; \#, $\mathrm{P}<0.05$ versus the corresponding group with siRNAcon. (B) Western blotting results showing that HIF-1 $\alpha$ siRNA reversed FG4592-induced increases in HIF$1 \alpha$ and PCNA expression. (C) Western blotting results showing that HIF- $1 \alpha$ siRNA effectively decreased hypoxia-induced increases in HIF- $1 \alpha$ and PCNA expression. (D) (E) The movement trajectories of the EpSCs in each group were recorded by a Zeiss imaging system. The velocity of each group is shown as the mean \pm SD. $N$, normoxia; $H$, hypoxia; *, $\mathrm{P}<0.05$ versus the $\mathrm{N}+$ siRNAcon group; \#, $\mathrm{P}<0.05$ versus the corresponding group with siRNAcon. 
Fig. 4. FG-4592 effectively accelerated wound healing in vivo. (A) Representative images of wounds in the FG-4592 and control groups from days 0-8. (B) The relative wound area at the indicated time points. Values represent the mean \pm SD $(n=8$ per group). *, $\mathrm{P}<0.05$ versus the control group. (C) Graph representing the time (days) to wound closure, which was significantly different between the control and FG-4592 groups. *, $\mathrm{P}<0.05$ versus the control group. (D) Representative HE-stained images of the wound edge on day 4 post-injury. The yellow double-headed arrows indicate the ends of the neo-epidermis. The area between the leading point (yellow triangle) and the first normal hair follicle (yellow triangle) is defined as the neo-epidermis. Bar $=200 \mu \mathrm{m}$. (E) The length of the neo-epidermis was measured along the basement membrane. Values represent the mean $\pm S D(n=6$ per group). *, $\mathrm{P}<0.05$ versus the control group.

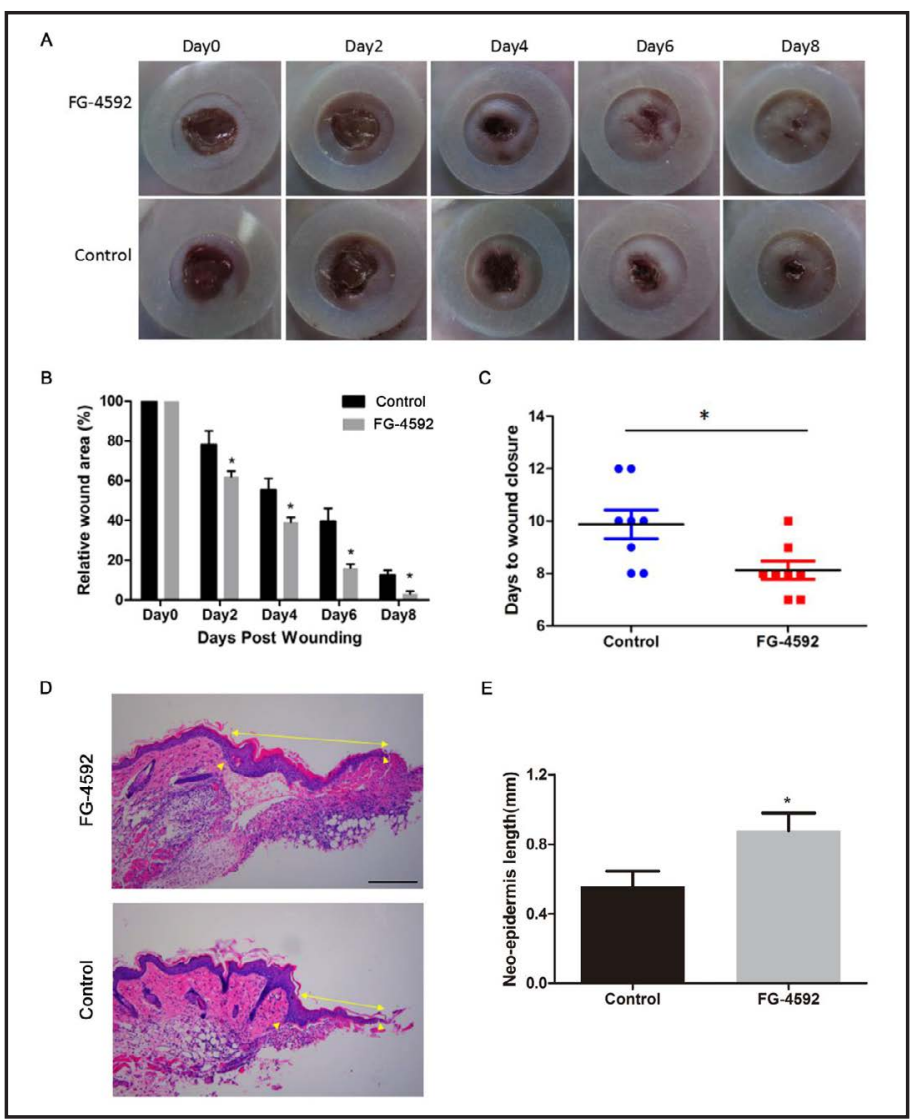

Fig. 5. Persistent up-regulation of HIF1 signalling by FG-4592 resulted in epidermal hyperplasia. (A) Representative HE-stained images of the wound site after the completion of wound healing (day 10 post-injury). Bar $=500$ $\mu \mathrm{m}$. (B) The mean neo-epidermis thickness was calculated as the area divided by the length, and the values represent the mean \pm SD of three samples per group. *, $\mathrm{P}<0.05$ versus the control group. (C) Western blotting re-

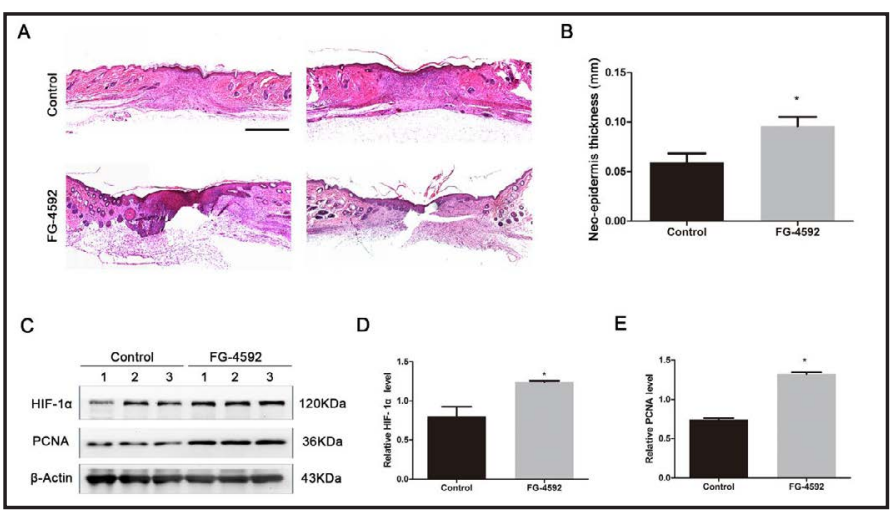
sults showing that FG-4592 effectively increased HIF-1 $\alpha$ and PCNA expression in the wound site tissue. Each group included three independent samples (serial numbers 1-3). (D) (E) Quantitative analysis of HIF-1 $\alpha$ and PCNA expression levels in each group. Values represent the mean \pm SD of three independent samples. * $\mathrm{P}<0.05$ versus the control group.

Persistent HIF-1 signalling up-regulation by FG-4592 results in epidermal hyperplasia

FG-4592 not only accelerated wound healing but also changed wound healing quality. HE staining demonstrated the presence of a thickened epidermis in the FG-4592 group compared with the control group (Fig. 5A) on day 10 post-injury. The thickness of the neo-epidermis in the mice in the control group (intraperitoneally injected with PBS) was $0.059 \pm 0.0095 \mathrm{~mm}$, whereas that in FG-4592-treated mice (intraperitoneal injected with FG4592) was $0.096 \pm 0.0093 \mathrm{~mm}\left({ }^{*} \mathrm{P}<0.05\right)$ (Fig. 5B). Furthermore, we assessed HIF- $1 \alpha$ and 
PCNA expression in the wound tissue on day 10 post-injury (three independent samples from each group). Western blotting and quantitative analysis showed that FG-4592 effectively increased HIF-1 $\alpha$ and PCNA expression in the FG-4592-treated group compared with the control group (Fig. 5C) and that the differences in HIF-1 $\alpha$ and PCNA expression between the two groups were statistically significant (Fig. 5D and E). These results confirmed that FG-4592 promotes cell proliferation but also indicate that HIF-1 $\alpha$ overexpression results in epidermal hyperplasia.

\section{Discussion}

In this study, we found that acute hypoxia caused EpSCs to switch from a quiescent state to an activated state with higher viability and motility, as well as an earlier proliferation peak. We investigated the mechanism underlying this phenomenon and found that HIF-1 $\alpha$ was involved in the process. Given that local oxygen tension is affected by many factors and is not easy to regulate, HIF- $1 \alpha$ may be used as a preferred target to induce EpSCs to participate in wound healing. We also demonstrated that FG-4592 promoted EpSC proliferation and motility via HIF- $1 \alpha$ stabilization and accelerated wound healing in vivo. Our findings show that HIF- $1 \alpha$ is an important target for accelerating wound healing and that FG-4592 is a promising new drug for wound care (Fig. 6).

Wound healing is a complex multistage process that requires the spatial and temporal orchestration of cellular and non-cellular components [23]. Hypoxia has been recognized as one of the prominent micro-environmental factors in tissue injury [32] and wound healing for decades [3,33]; however, the effect of hypoxia on wound healing remains controversial [23, 34-37]. As skin seed cells, EpSCs and their offspring undergo slow, rhythmic processes of proliferation and differentiation in physiological conditions. After injury, more EpSCs are activated and participate in wound healing. We compared EpSCs cultured in normoxia with those cultured in hypoxia and found that EpSCs cultured in hypoxia $\left(2 \% \mathrm{O}_{2}\right)$ had higher viability and motility, a broader range of movement, and even an earlier proliferation peak than EpSCs cultured in normoxia (Fig. 1). Our findings suggest that acute hypoxia may be one of the factors that triggers the switching of EpSCs from a quiescent state to an active state.

Fig. 6. Schematic model of acute hypoxia triggering EpSC activation through HIF-1 signalling. After injury, high oxygen consumption and vascular injury result in partial hypoxia. Acute hypoxia in the wound edge causes EpSCs to switch from a quiescent state to an activated state with a higher viability and motility, as well as an earlier proliferation peak, through up-regulation of HIF-1 signalling. FG-4592, a firstclass, potent HIF-PHI, simulated the positive

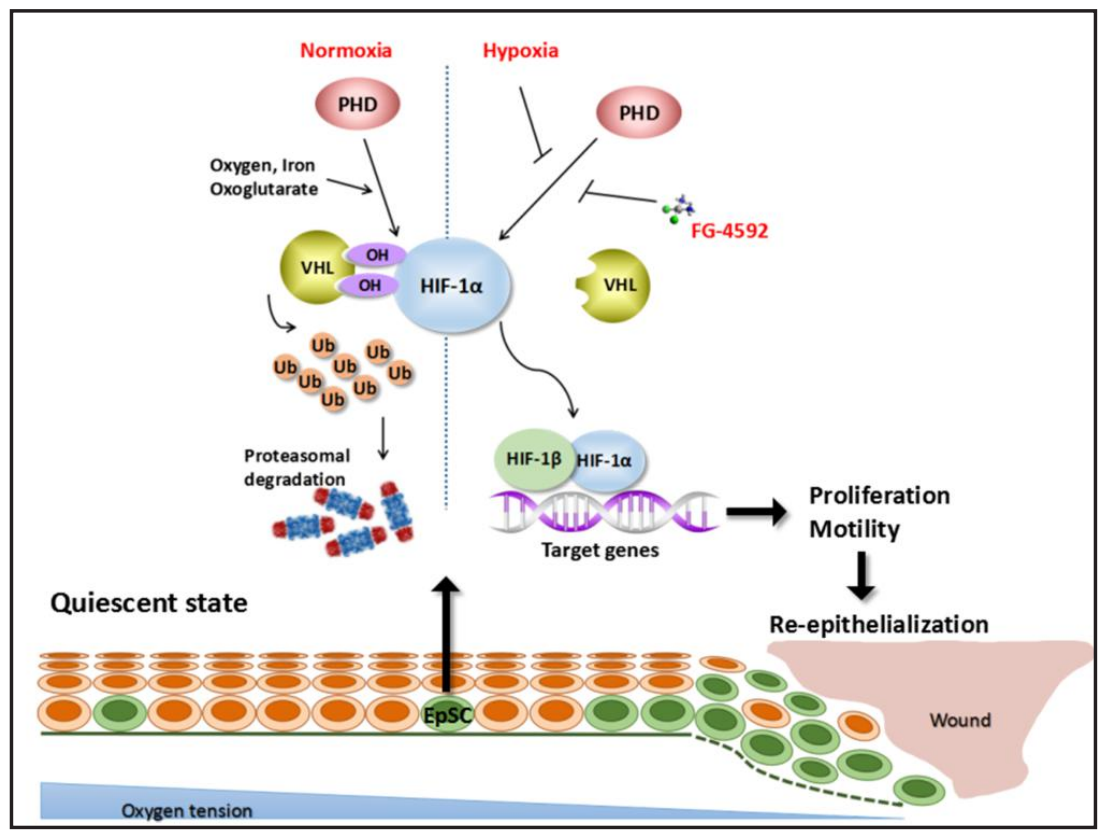
effect of acute hypoxia on EpSC activation and accelerated re-epithelialization during wound healing. 
Hypoxic responses, which are mediated mainly by a master oxygen homeostasis transcription factor, HIF-1, have been shown to be critically involved in many important life processes, including wound healing [2, 23]. However, whether HIF-1 mediates the hypoxic regulation of EpSC activation is still poorly understood. FG-4592 (a prolyl hydroxylase inhibitor that stabilizes HIF-1 $\alpha$ in normoxia) [21, 29] and KC7F2 (a selective inhibitor of HIF- $1 \alpha$ transcription) [38] were used to regulate HIF-1 $\alpha$ expression. We found that the HIF-1 signalling pathway plays an important role in EpSC activation (Fig. 2).

Gaining a better understanding of this mechanism may provide insights necessary for the development of a novel therapeutic strategy for accelerating wound healing. Regarding EpSC activation, HIF stabilization by hypoxia or a hypoxia-inducible factor prolyl hydroxylase inhibitor (HIF-PHI) induces the activation of a group of target genes, including genes related to cell proliferation [39], viability and motility [2, 4, 40]. Stabilizing HIF with a small-molecule HIF-PHI may be an innovative therapeutic approach to wound treatment. More importantly, FG-4592 is a first-class, potent HIF-PHI and was shown to be safe in a clinical trial regarding chronic kidney disease [27]. Given that FG-4592 stabilizes both HIF-1 and HIF-2, we used siRNA HIF- $1 \alpha$ to determine whether hypoxia- and FG-4592-induced EpSC activation are HIF1 signalling-dependent processes (Fig. 3).

In our in vitro study, FG-4592 was used to treat mice with full-thickness excisional wounds. The drug dose was determined according to a recent study, which revealed that FG-4592 plays a role in the prevention of retinopathy of prematurity [29]. Intraperitoneal injection of FG-4592 effectively increased HIF-1 $\alpha$ expression in skin (Fig. 5C-E) and accelerated the wound closure (Fig. 4). More interestingly, the mice in the FG-4592 group had a thicker neo-epidermis than the mice in the control group (Fig. 5A and B). We inferred that this epidermal thickening had two causes. First, the wound-healing process ended as the oxygen tension normalized [4], indicating that the epidermal thickening was due to the effects of hypoxia on EpSCs. Second, exogenous FG-4592 kept the EpSCs in an activated state instead of a quiescent state. Coincidentally, another study revealed that ageing K14-Cre/ HIF- $1 \alpha^{\text {flox/flox }}$ mice displayed a phenotype characterized by epidermal thinning and dermal atrophy [25]. These results confirm that HIF-1 $\alpha$ is an important positive regulator of wound healing, especially the re-epithelialization process, in which epidermal stem cells and their offspring are deeply involved.

For burn patients, epidermal thickening is doubtless a good thing because a thickened epidermis is abrasion resistant and displays less blistering. Although concerns exist regarding the possibility that epidermal thickening promotes tumourigenesis, it is worth noting that epidermal thickening had no clear tumourigenic effects in PHD-2 knockout mice [24]. FG-4592, a prolyl hydroxylase inhibitor, is now in phase three clinical trials regarding the treatment of renal anaemia in patients with chronic kidney disease [26]. Moreover, recent studies reported FG-4592 can be applied in the treatment of retinal disease [28, 29] and spinal cord injury [21]. These studies indicate that FG-4592 has immense therapeutic potential in HIF-1 signalling-related disease. However, additional clinical trials on the safety and efficacy of FG-4592 in wound care are urgently required so that this therapeutic strategy can be moved from the bench to the bedside.

\section{Conclusion}

Taken together, our results illustrate that HIF-1 signalling contributes to hypoxiainduced activation of EpSCs at the wound edge, which accelerates wound healing. Injection of exogenous FG-4592 simulated the positive effect of hypoxia on the switching of EpSCs from a quiescent state to an activated state. Understanding this mechanism may enable the development of a novel and precise wound care strategy.

\section{Acknowledgements}

This research was supported by the National Key Research and Development Program of China (No. 2017YFC1103302), the Key Program of National Natural Science Foundation of 


\section{Cellular Physiology Cell Physiol Biochem 2018;46:2460-2470

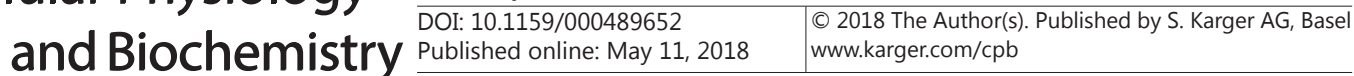 \\ Tang et al.: FG-4592 Accelerates Cutaneous Wound Healing}

China (No.81430042), the State Key Development Program for Basic Research in China (No. 2012CB518101) and the research fund of the State Key Laboratory of Trauma, Burns and Combined Injury (SKLZZ201203, SKLZZ2012 (III) 01).

\section{Disclosure Statement}

The authors declare that they have no conflicts of interest.

\section{References}

> Li H, Yao Z, He W, Gao H, Bai Y, Yang S, Zhang L, Zhan R, Tan J, Zhou J, Takata M, Wu J, Luo G: P311 induces the transdifferentiation of epidermal stem cells to myofibroblast-like cells by stimulating transforming growth factor beta1 expression. Stem Cell Res Ther 2016;7:175.

-2 Rezvani HR, Ali N, Nissen LJ, Harfouche G, de Verneuil H, Taieb A, Mazurier F: HIF-1 $\alpha$ lpha in epidermis: Oxygen sensing, cutaneous angiogenesis, cancer, and non-cancer disorders. J Invest Dermatol 2011;131:1793-1805.

- Ninikoski J, Heughan C, Hunt TK: Oxygen tensions in human wounds. J Surg Res 1972;12:77-82.

4 Tang D, Yan T, Zhang J, Jiang X, Zhang D, Huang Y: Notch1 signaling to hypoxia-induced high expression of integrin $\beta 1$ in keratinocyte migration. Sci Rep UK 2017;7:43926.

5 Wang X, Zhang Y, Wang H, Zhao G, Fa X: MicroRNA-145 aggravates Hypoxia-Induced injury by targeting rac1 in h9c2 cells. Cell Physiol Biochem 2017;43:1974-1986.

6 Gong LC, Xu HM, Guo GL, Zhang T, Shi JW, Chang C: Long Non-Coding RNA h19 protects h9c2 cells against Hypoxia-Induced injury by targeting MicroRNA-139. Cell Physiol Biochem 2017;44:857-869.

7 Thangarajah H, Yao D, Chang EI, Shi Y, Jazayeri L, Vial IN, Galiano RD, Du XL, Grogan R, Galvez MG, Januszyk M, Brownlee M, Gurtner GC: The molecular basis for impaired hypoxia-induced VEGF expression in diabetic tissues. Proc Natl Acad Sci USA 2009;106:13505-13510.

8 Duscher D, Januszyk M, Maan ZN, Whittam AJ, Hu MS, Walmsley GG, Dong Y, Khong SM, Longaker MT, Gurtner GC: Comparison of the hydroxylase inhibitor dimethyloxalylglycine and the iron chelator deferoxamine in diabetic and aged wound healing. Plast Reconstr Surg 2017;139:695e-706e.

-9 Semenza GL: Vascular responses to hypoxia and ischemia. Arterioscler Thromb Vasc Biol 2010;30:648-652.

10 Thiersch M, Rimann M, Panagiotopoulou V, Ozturk E, Biedermann T, Textor M, Luhmann TC, Hall H: The angiogenic response to PLL-g-PEG-mediated HIF-1 $\alpha$ lpha plasmid DNA delivery in healthy and diabetic rats. Biomaterials 2013;34:4173-4182.

11 Botusan IR, Sunkari VG, Savu O, Catrina AI, Grunler J, Lindberg S, Pereira T, Yla-Herttuala S, Poellinger L, Brismar K, Catrina SB: Stabilization of HIF-1 $\alpha$ lpha is critical to improve wound healing in diabetic mice. Proc Natl Acad Sci USA 2008;105:19426-19431.

12 Sarkar K, Fox-Talbot K, Steenbergen C, Bosch-Marce M, Semenza GL: Adenoviral transfer of HIF-1 $\alpha$ lpha enhances vascular responses to critical limb ischemia in diabetic mice. Proc Natl Acad Sci USA 2009;106:18769-18774.

13 Hsu Y, Li L, Fuchs E: Emerging interactions between skin stem cells and their niches. Nat Med 2014;20:847856.

$>14$ Goldstein J, Fletcher S, Roth E, Wu C, Chun A, Horsley V: Calcineurin/Nfatc1 signaling links skin stem cell quiescence to hormonal signaling during pregnancy and lactation. Genes Dev 2014;28:983-994.

15 Zhou T, Yang Z, Chen Y, Chen Y, Huang Z, You B, Peng Y, Chen J: Estrogen accelerates cutaneous wound healing by promoting proliferation of epidermal keratinocytes via Erk/Akt signaling pathway. Cell Physiol Biochem 2016;38:959-968.

16 Keith B, Simon MC: Hypoxia-inducible factors, stem cells, and cancer. Cell 2007;129:465-472.

17 Janich P, Pascual G, Merlos-Suarez A, Batlle E, Ripperger J, Albrecht U, Cheng HY, Obrietan K, Di Croce L, Benitah SA: The circadian molecular clock creates epidermal stem cell heterogeneity. Nature 2011;480:209-214.

18 Liu Z, Tu K, Wang Y, Yao B, Li Q, Wang L, Dou C, Liu Q, Zheng X: Hypoxia accelerates aggressiveness of hepatocellular carcinoma cells involving oxidative stress, Epithelial-Mesenchymal transition and NonCanonical hedgehog signaling. Cell Physiol Biochem 2017;44:1856-1868. 


\section{Cellular Physiology Cell Physiol Biochem 2018;46:2460-2470 \begin{tabular}{l|l} 
and Biochemistry Published onlıne: May 11, 2018 & $\begin{array}{l}\text { (c) } 2018 \text { The Author(s). Published by S. Karger AG, Basel } \\
\text { www.karger.com/cpb }\end{array}$
\end{tabular}}

19 He M, Zhan M, Chen W, Xu S, Long M, Shen H, Shi Y, Liu Q, Mohan M, Wang J: MiR-143-5p deficiency triggers EMT and metastasis by targeting HIF-1 $\alpha$ lpha in gallbladder cancer. Cell Physiol Biochem 2017;42:20782092.

20 Hou SY, Li YP, Wang JH, Yang SL, Wang Y, Wang Y, Kuang Y: Aquaporin-3 inhibition reduces the growth of NSCLC cells induced by hypoxia. Cell Physiol Biochem 2016;38:129-140.

-21 Wu K, Zhou K, Wang Y, Zhou Y, Tian N, Wu Y, Chen D, Zhang D, Wang X, Xu H, Zhang X: Stabilization of HIF$1 \alpha$ by FG-4592 promotes functional recovery and neural protection in experimental spinal cord injury. Brain Res 2016;1632:19-26.

22 Schofield CJ, Ratcliffe PJ: Oxygen sensing by HIF hydroxylases. Nat Rev Mol Cell Biol 2004;5:343-354.

23 Ruthenborg RJ, Ban JJ, Wazir A, Takeda N, Kim JW: Regulation of wound healing and fibrosis by hypoxia and hypoxia-inducible factor-1. Mol Cells 2014;37:637-643.

24 Zimmermann AS, Morrison SD, Hu MS, Li S, Nauta A, Sorkin M, Meyer NP, Walmsley GG, Maan ZN, Chan DA, Gurtner GC, Giaccia AJ, Longaker MT: Epidermal or dermal specific knockout of PHD-2 enhances wound healing and minimizes ischemic injury. PLoS One 2014;9:e93373.

25 Rezvani HR, Ali N, Serrano-Sanchez M, Dubus P, Varon C, Ged C, Pain C, Cario-Andre M, Seneschal J, Taieb A, de Verneuil H, Mazurier F: Loss of epidermal hypoxia-inducible factor-1alpha accelerates epidermal aging and affects re-epithelialization in human and mouse. J Cell Sci 2011;124:4172-4183.

-26 Provenzano R, Besarab A, Sun CH, Diamond SA, Durham JH, Cangiano JL, Aiello JR, Novak JE, Lee T, Leong R, Roberts BK, Saikali KG, Hemmerich S, Szczech LA, Yu KH, Neff TB: Oral Hypoxia-Inducible factor prolyl hydroxylase inhibitor roxadustat (FG-4592) for the treatment of anemia in patients with CKD. Clin J Am Soc Nephrol 2016;11:982-991.

-27 Besarab A, Provenzano R, Hertel J, Zabaneh R, Klaus SJ, Lee T, Leong R, Hemmerich S, Yu KH, Neff TB: Randomized placebo-controlled dose-ranging and pharmacodynamics study of roxadustat (FG-4592) to treat anemia in nondialysis-dependent chronic kidney disease (NDD-CKD) patients. Nephrol Dial Transplant 2015;30:1665-1673.

28 Liu H, Zhu H, Li T, Zhang P, Wang N, Sun X: Prolyl-4-Hydroxylases inhibitor stabilizes HIF-1 $\alpha$ lpha and increases mitophagy to reduce cell death after experimental retinal detachment. Invest Ophthalmol Vis Sci 2016;57:1807-1815.

29 Hoppe G, Yoon S, Gopalan B, Savage AR, Brown R, Case K, Vasanji A, Chan ER, Silver RB, Sears JE: Comparative systems pharmacology of HIF stabilization in the prevention of retinopathy of prematurity. Proc Natl Acad Sci USA 2016;113:E2516-E2525.

30 Kaur P: Interfollicular epidermal stem cells: Identification, challenges, potential. J Invest Dermatol 2006;126:1450-1458.

-31 Galiano RD, Michaels JT, Dobryansky M, Levine JP, Gurtner GC: Quantitative and reproducible murine model of excisional wound healing. Wound Repair Regen 2004;12:485-492.

32 Shi H, Zhang X, He Z, Wu Z, Rao L, Li Y: Metabolites of hypoxic cardiomyocytes induce the migration of cardiac fibroblasts. Cell Physiol Biochem 2017;41:413-421.

-33 Hunt TK, Zederfeldt B, Goldstick TK: Oxygen and healing. Am J Surg 1969;118:521-525.

-34 Yan T, Zhang J, Tang D, Zhang X, Jiang X, Zhao L, Zhang Q Zhang D, Huang Y: Hypoxia regulates mTORC1Mediated keratinocyte motility and migration via the AMPK pathway. PLoS One 2017;12:e169155.

-35 Zhang J, Zhang D, Yan T, Jiang X, Zhang C, Zhao L, Li L, Tang D, Zhang Q, Jia J, Zhang J, Huang Y: BNIP3 promotes the motility and migration of keratinocyte under hypoxia. Exp Dermatol 2017;26:416-422.

-36 Sano H, Ichioka S, Sekiya N: Influence of oxygen on wound healing dynamics: Assessment in a novel wound mouse model under a variable oxygen environment. PLoS One 2012; 7:e50212.

37 Gordillo GM, Sen CK: Revisiting the essential role of oxygen in wound healing. Am J Surg 2003;186:259263.

38 Narita T, Yin S, Gelin CF, Moreno CS, Yepes M, Nicolaou KC, Van Meir EG: Identification of a novel small molecule HIF-1 $\alpha$ lpha translation inhibitor. Clin Cancer Res 2009;15:6128-6136.

-39 Keely S, Glover LE, MacManus CF, Campbell EL, Scully MM, Furuta GT, Colgan SP: Selective induction of integrin beta1 by hypoxia-inducible factor: Implications for wound healing. FASEB J 2009;23:1338-1346.

40 Grose R, Hutter C, Bloch W, Thorey I, Watt FM, Fassler R, Brakebusch C, Werner S: A crucial role of beta 1 integrins for keratinocyte migration in vitro and during cutaneous wound repair. Development 2002;129:2303-2315. 